Int. J. Dev. Biol. 51: 361-370 (2007)

doi: $10.1387 / \mathrm{ijdb} .072301 \mathrm{cl}$

Original Article

\title{
An activating mutation in the PDGF receptor-beta causes abnormal morphology in the mouse placenta
}

\author{
CAMILLA LOOMAN ${ }^{1}$, TONG SUN ${ }^{2}$, YANG YU ${ }^{2}$, AGATA ZIEBA ${ }^{1}$, AIVE AHGREN ${ }^{1}$, RICARDO FEINSTEIN ${ }^{3}$, HENRIK \\ FORSBERG ${ }^{1}$, CARINA HELLBERG ${ }^{1}$, CARL-HENRIK HELDIN ${ }^{1}$, XIAO-OUN ZHANG ${ }^{4}$, KARIN FORSBERG- \\ NILSSON ${ }^{4}$, NELSON KHOO ${ }^{5}$, REINALD FUNDELE²and RAINER HEUCHEL ${ }^{1, *}$ \\ ${ }^{1}$ Ludwig Institute for Cancer Research, Uppsala University, ${ }^{2}$ Department of Development and Genetics, Uppsala University, ${ }^{3}$ National \\ Veterinary Institute, ${ }^{4}$ Department of Medical Biochemistry and Microbiology, Uppsala University, Uppsala, Sweden \\ and Umeå Biotech Incubator, Umeå, Sweden
}

\begin{abstract}
An oncogenic D842V mutation in the platelet-derived growth factor (PDGF) $\alpha$ receptor (Pdgfra) has recently been described in patients with gastrointestinal stromal tumors. In order to test if the same mutation would confer oncogenic properties to the homologous PDGF $\beta$-receptor (Pdgfrb), the corresponding aspartic acid residue at position 849 of Pdgfrb was changed into valine (D849V) using a knock-in strategy. This mutation turned out to be dominantly lethal and caused death even in chimeras (from 345 transferred chimeric blastocysts, no living coat chimeras were detected). Experiments employing mouse embryonic fibroblasts (MEFs) indicated hyperactivity of the mutant receptor. The mutant receptor was phosphorylated in a ligandindependent manner and, in contrast to wild-type MEFs, mutant cells proliferated even in the absence of ligand. Knockout experiments have previously indicated a role for Pdgfrb in placental development. We therefore analyzed wild-type and Pdgfrb D849V chimeric placentas from different gestational stages. No differences were detected at embryonic days 11.5 and 13.5 ( $n=4)$. At embryonic day 17.5 , however, chimeric placentas $(n=3 / 4)$ displayed abnormalities both in the labyrinth and in the chorionic plate. The changes included hyper-proliferation of alpha-smooth muscle actin and platelet/endothelial cell adhesion molecule-1 positive cells in the labyrinth and cells in the chorionic plate. In addition, the fetal blood vessel compartment of the labyrinth was completely disorganized.
\end{abstract}

KEY WORDS: gene targeting, pericyte, labyrinthine layer, growth factor signaling

\section{Introduction}

The family of platelet-derived growth factors (PDGFs) has been shown to drive cellular responses including cell proliferation, survival and migration. Coordinated signalling via the PDGFs and their cognate tyrosine kinase receptors is required for normal developmental as well as for normal post-natal life. Knockout studies have, for instance, demonstrated that Pdgfb/ Pdgfrb signalling is essential for the proper recruitment of vascular smooth muscle cells and pericytes to developing blood vessel walls (Lindahl et al., 1997; Hellstrom et al., 1999; and reviewed in Betsholtz, 2004). Mutant embryos homozygous for deletion of Pdgfrb or Pdgfb appear normal until E1619 , at which time there is a sudden onset of edema formation, dilation of the heart and large blood vessels and dilation and rupture of capillaries. Thus it seems that the Pdgfrb and Pdgfb are dispensable until late in embryonic development, when rising hydrostatic pressure requires a fully functional blood vessel system. Histologically, the Pdgfb and Pdgfrbknockouts present with abnormal kidney glomeruli, capillary microaneurysms, arterial smooth muscle cell hypoplasia, cardiac muscle hypotrophy, placenta defects and widespread edema and haemorrhages. Both Pdgfb and Pdgfrb null mutant mice die perinatally from microvascular bleedings caused by shortage of vascular mural cells.

The placenta, a transient organ whose function is essential

Abbreviations used in this paper: ASMA, alpha smooth muscle actin; BrdU, Bromodeoxyuridine; GIST, gastrointestinal stromal tumor; ES, embryonic stem cell; MEF, mouse embryonic fibroblast; PDGF, platelet derived growth factor; pdgfr, platelet derived growth factor receptor; PECAM, platelet/ endothelial cell adhesion molecule.

\footnotetext{
*Address correspondence to: Rainer Heuchel. Ludwig Institute for Cancer Research, Uppsala University, BMC, 75124 Uppsala, Sweden. Fax: +46-18-160420. e-mail: Rainer.Heuchel@LICR.uu.se
} 
for the development of all eutherian mammals, needs a wellcoordinated Pdgfb/Pdgfrb signalling for its proper development (Ohlsson et al., 1999). One of the major functions of the placenta is the nutrient-waste exchange between mother and fetus, which takes place in the labyrinthine layer, where the fetal and maternal circulatory systems are in close contact. Here a fine, dense network of fetal capillaries is intermingled with lacunae of maternal blood to form a large contact surface for the nutrient-waste exchange (Rossant and Cross, 2001 and references therein). Pdgfb and Pdgfrb null mutant placentas have reduced numbers of pericytes, a reduced fetal vessel density and an increased vessel diameter indicating that Pdgfb/Pdgfrb signalling is important for the proper organization of the labyrinth (Ohlsson et al., 1999).

Pdgfb/Pdgfrb has also been linked to a number of different hyperproliferative disorders including atherosclerosis, fibrotic conditions and malignant diseases (reviewed in Bonner, 2004; Ostman, 2004; Raines, 2004). Recently, a subgroup of patients with gastrointestinal stromal tumors (GISTs) was found to carry activating mutations in the closely related Pdgfra. One of these mutations, a substitution of valine for the highly conserved aspartic acid at amino acid position 842 (D842V) in the activa-

A
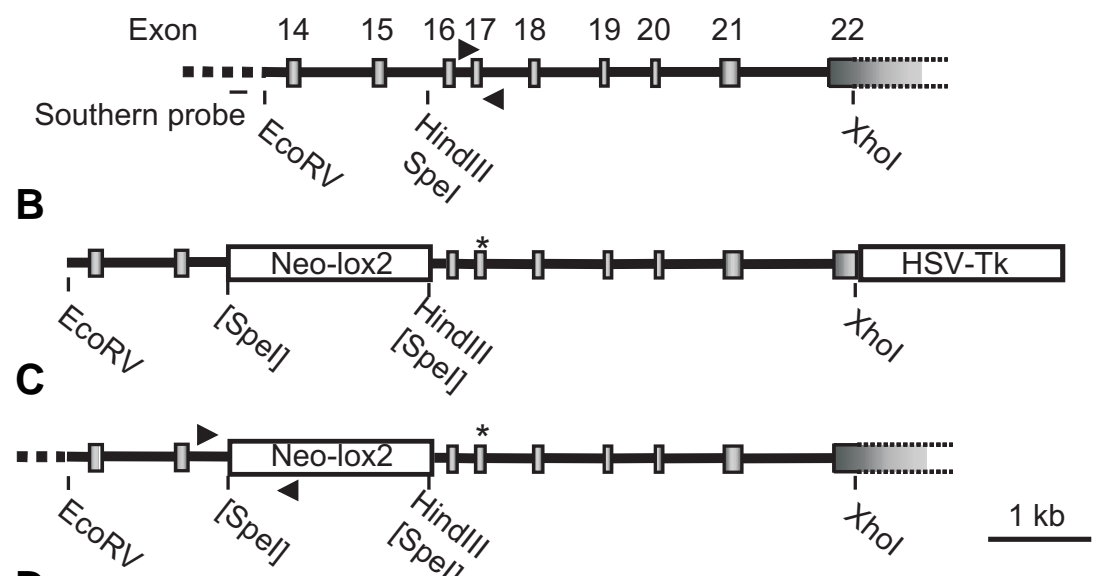

D

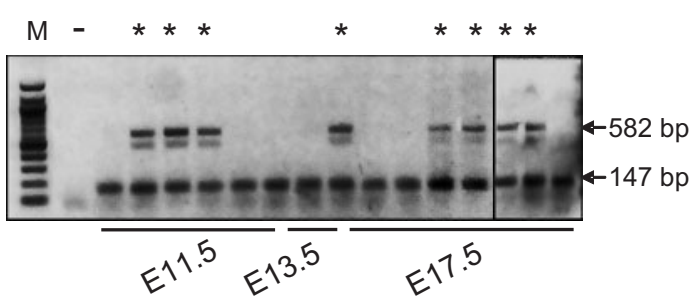

Fig. 1. Introduction of a D849V mutation into Pdgfrb. The intron/exon structure of the mouse Pdgfrb is schematically represented before (A) and after (C) the targeting event. The targeting vector with the genomic arms and the two selection cassettes, but without the bacterial vector backbone, is shown in (B). The asterisks in (B) and $(C)$ indicate the position of the D849V point mutation and the arrowheads show the position of the primers used for genotyping of wild-type (A) and mutant (C) alleles. The probe used for Southern blot analysis is shown in (A). Chimeric and wild-type embryos were identified by PCR using genomic DNA prepared from tail (E17.5) or head (E11.5 and E13.5) (D). Wild-type and mutant alleles result in 147 base pair and 582 base pair products, respectively. 100-base pair ladder (M), negative water control (-) and PCR products from chimeric embryos $\left(^{*}\right)$ are indicated. tion loop of the kinase domain, is homologous to tumor-related mutations of KIT and other receptor tyrosine kinases (Heinrich ES) cells. In a previous study, we had introduced a similar receptor, mice homozygous for the mutation showed no obviproliferation both in vitro, in cultured mouse embryonic fibroblasts (MEFs) and in vivo in the labyrinthine layer and the chorionic plate of the late gestation mouse placenta. D849V chimeric E17.5 placentas also showed a strongly altered morphology.

\section{Results}

\section{Generation of mutant ES cell lines and chimeric placentas}

A change from aspartic acid to valine was introduced at amino acid residue 849 of the mouse Pdgfrb using the targeting vector shown in Figure 1. The linearized construct was electroporated into GS-1 ES cells and correctly recombined clones were identified by PCR and Southern blot analysis. The presence of the point mutation was confirmed by DNA sequencing (data not shown).

Two independent mutant ES cell clones were used for repeated blastocyst injection/transfer (290 from clone 1 and 55 from clone 2), but neither of them was able to generate viable coat chimeras. A correctly targeted (neo cassette in the correct position), but otherwise wild-type ES cell clone from the same electroporation as the mutant clones was injected in parallel and resulted in germline transmission at a high frequency. This proved a high quality of the original ES cell line and indicated that the D849V mutation of the Pdgfrb had deleterious effects on development. Previous studies have shown that lack of either Pdgfrb or its ligand, Pdgfb, affects the development of the mouse placenta (Ohlsson et al., 1999). To investigate if the Pdgfrb D849V mutation had any effects on placental development, we isolated chimeric and wild-type placentas at embryonic day 11.5, 13.5 and 17.5 (E11.5, E13.5, E17.5; Table 1). The genotype of the conceptuses was determined by PCR (Fig. 1D). All but one of the E11.5 and E13.5 chimeric embryos ( 3 


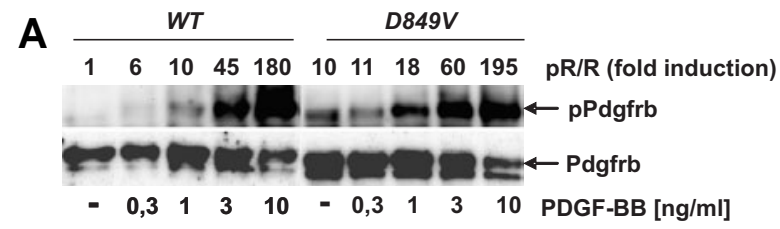

B

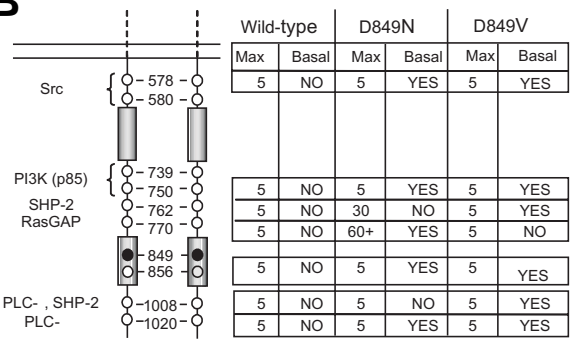

C

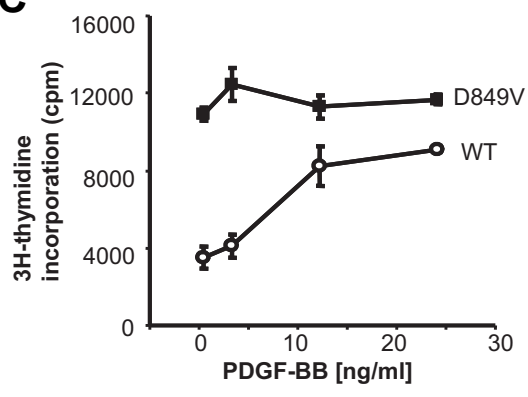

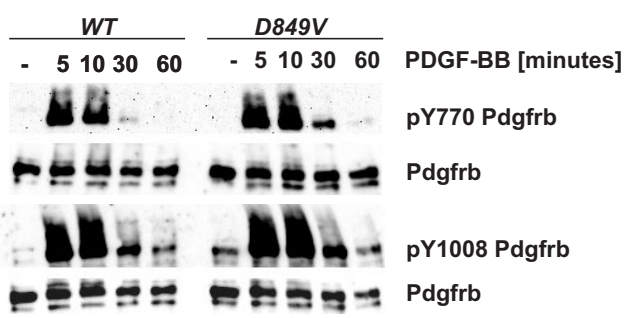
basal wild-type condition (=1) are shown. A summary of the individual tyrosine phosphorylation differences between wild-type, D849N and D849V mutant PDGF receptors as established by the use of phosphorylation site-specific antibodies is shown to the left in (B). Serum-starved cells were either left unstimulated (-) or stimulated with PDGF-BB $(20 \mathrm{ng} / \mathrm{ml})$ for the indicated times. "Max", time in minutes at which the phosphorylation maximum occurred in the time course performed; "Basal", ligand-independent phosphorylation. Representative blots stained sequentially for phosphorylation at specific tyrosine residues and Pdgfrb are shown to the right. The mitogenic response of wild-type lopen circle) and D849V mutant (filled squares) MEFs to PDGF-BB is shown in (C). Mitogenesis was assayed by incubating serum-starved cells with the indicated amounts of PDGF-BB in the presence of $\left[{ }^{3} \mathrm{H}\right]$ thymidine. For analysis, $\left[{ }^{3} \mathrm{H}\right]$ thymidine radioactivity was precipitated using trichloracetic acid and the samples were measured in a scintillation counter. Data of a representative experiment including mean values of triplicates and standard deviations are depicted. alive/4) were alive. At E17.5, however, only one, from a total of four chimeric fetuses, was alive. The other three were late resorptions, as it was clearly evident that organogenesis had occurred. The major structures, such as head, eyes, tail and limbs could still be recognized (see Fig. 3). We did not observe any difference in placental weights at any of the gestational stages examined (data not shown).

The D849V mutation causes ligand-independent phosphorylation of the receptor and ligand-independent proliferation of mutant embryonic fibroblasts

Receptor tyrosine kinases like PDGF receptors are activated by ligand binding which results in auto-phosphorylation of multiple tyrosine residues within the intracellular part of the receptor. The phosphorylated tyrosine residues serve as docking sites for proteins initiating different signalling pathways, the net result of which determines the final cellular response (Heldin and Westermark, 1999). An oncogenic D842V mutation in Pdgfra, homologous to the Pdgfrb D849V mutation described here, has previously been shown to result in constitutive phosphorylation

Table 1 (to the right). The numbers of manipulated blastocysts (injected with PdgfrbD849V mutant ES cells) and unmanipulated (non-injected) control blastocysts transferred into pseudo-pregnant mice are shown together with the feto-placental units isolated at different gestational stages.

${ }^{A}$ Early resorptions. Small dark moles with no distinct structures. PCR genotyping not possible anymore.

BLate resorptions. Organogenesis had occurred and major structures such as head, eyes, tail and limbs could still be recognized.

Wt Pdgfrb wild type as determined by PCR genotyping

Chim Pdgfrb D849V chimeras as determined by PCR genotyping. and activation of the Pdgfra (Heinrich et al., 2003). To test whether the D849V mutant Pdgfrb exhibited similar properties, we studied the tyrosine phosphorylation status in wild-type and heterozygous mutant mouse embryonic fibroblasts (MEFs). Under non-stimulating conditions, there was a 10-fold increase in the level of tyrosine-phosphorylated Pdgfrb in the mutant MEFs compared to wild-type MEFs (Fig. 2A). The receptors from mutant cells also showed a slightly higher auto-phosphorylation upon stimulation with low concentrations of PDGF-BB (Fig. 2A). When examining the tyrosine phosphorylation kinetics for seven individual autophosphorylation sites of the Pdgfrb, we observed that, in mutant MEFs, the majority of these seven tyrosines were phosphorylated in the absence of ligand. This was in sharp contrast to the wild-type MEFs, where the receptor was only phosphorylated in the presence of ligand (Fig. 2B). Pdgfb is known to be a powerful mitogen for mesenchymal cells. To test the mitogenic response of

\section{TABLE 1}

\section{BLASTOCYSTS AND FETO-PLACENTAL UNITS}

\begin{tabular}{|c|c|c|c|}
\hline & E 11.5 & E 13.5 & E 17.5 \\
\hline \multicolumn{4}{|l|}{ Unmanipulated } \\
\hline transferred & 40 & 24 & 24 \\
\hline live & 15 & 3 & 11 \\
\hline early resorptions ${ }^{A}$ & 3 & 7 & 2 \\
\hline late resorptions ${ }^{B}$ & 0 & 0 & 0 \\
\hline \multicolumn{4}{|l|}{ Manipulated } \\
\hline transferred & 40 & 24 & 24 \\
\hline live & $9^{\mathrm{Wt}}+2^{\mathrm{Chim}}$ & $12^{\mathrm{Wt}}+1^{\mathrm{Chim}}$ & $6^{\mathrm{Wt}}+1^{\mathrm{Chim}}$ \\
\hline early resorptions ${ }^{A}$ & 9 & 0 & 4 \\
\hline late resorptions ${ }^{B}$ & 1 Chim & 0 & $3^{\text {Chim }}$ \\
\hline
\end{tabular}



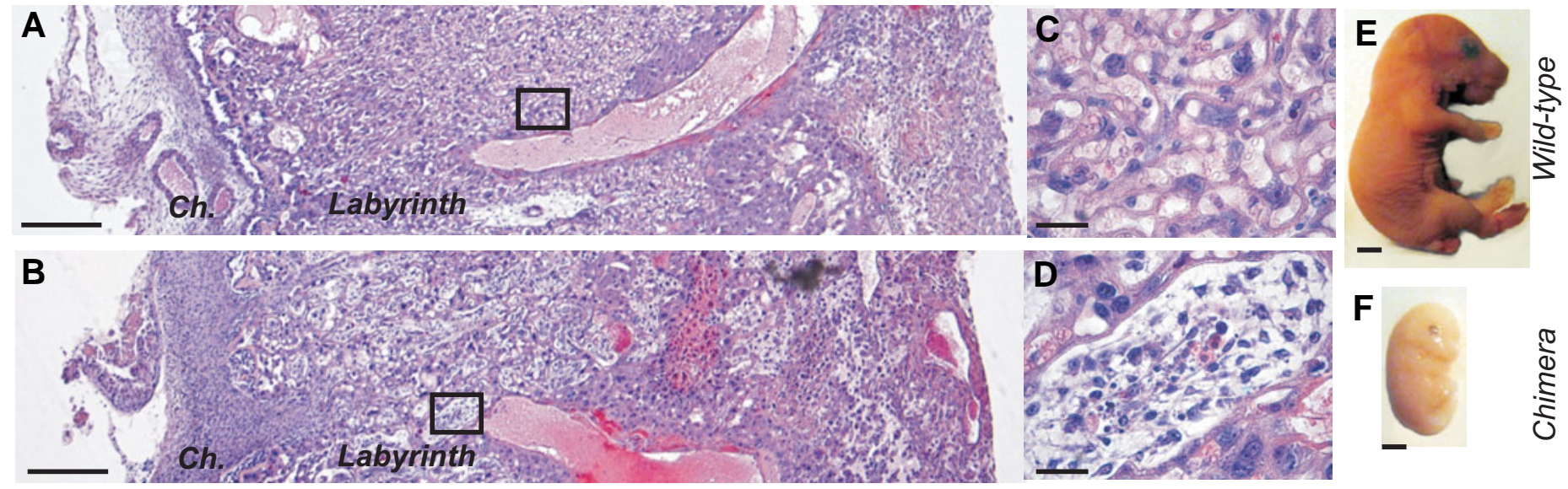

$\mathbf{F}$

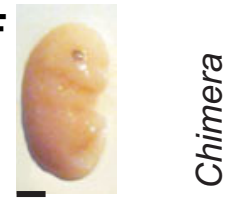

Fig. 3. Morphology of E17.5 wild-type and Pdgfrb D849V chimeric placentas. Wild-type (A) and chimeric (B) placentas from E17.5 fetuses stained with Mayer's hematoxylin-eosin are shown. (C,D) Higher magnifications of the labyrinthine layers from wild type $(A)$ and chimeric (B) placentas, black rectangles. Labyrinth and chorionic plate (Ch.) are indicated. One representative wild-type (E) and chimeric (F) E17.5 fetus are also shown. Note that the fetuses have been fixed in paraformaldehyde and that the tail has been used for genotyping. Bars: (A,B) $200 \mu m ;(C, D), 25 \mu m ;(E, F) 2$ mm.

wild-type and mutant MEFs, serum-starved cells were incubated with increasing amounts of PDGF-BB in the presence of $\left[{ }^{3} \mathrm{H}\right]$ thymidine. In contrast to wild-type cells, MEFs carrying the mutant receptor displayed a high rate of proliferation, even in the absence of ligand (Fig. 2C).

\section{Abnormal morphology in D849V chimeric placentas}

Consistent with the previous findings that normal placental development is dependent on Pdgfb/Pdgfrb signalling (Ohlsson et al., 1999), histological examination of E17.5 placentas ( $n=4$ for both wild-type and chimeric placentas) revealed a striking difference between wild-type placentas and the D849V chimeric placentas $(n=3 / 4$; all 3 chimeric placentas showing a phenotype were attached to dead fetuses). In normal E17.5 placentas, the fetal vasculature enters the placenta through the chorionic plate and forms a dense network of vessels in the labyrinthine layer (Fig. 3A and C). In E17.5 chimeric placentas ( $n=3 / 4)$, however, no or very few fetal vessels were found in the chorionic plate and the fetal blood vessel compartment of the labyrinthine layer was completely disorganized and largely replaced by island-like structures (Fig. 3B and D). These island-like structures contained stellate or fusiform cells with thin, fibrillary cytoplasmic extensions. At sites, the islands assumed glomus-like features, showing stellate cells irregularly arranged around a central vessel. No morphological changes were observed in the placenta attached to the E17.5 living chimeric fetus. We were also unable to detect any morphological and histological differences between placentas from wild-type and chimeric embryos at E11.5 and E13.5 (data not shown). No obvious labyrinthine trophoblast phenotype was observed.

\section{Contribution of mutant cells to the D849V chimeric placentas}

In order to find a possible explanation for the lack of a phenotype in one of the four E17.5 chimeric placentas, the relative contribution of mutant cells to the chimeric placentas was determined. To this end, genomic DNA was isolated from the labyrinthine layer of the placentas and tested for the relative presence of the mutant allele by semi-quantitative PCR. The three E17.5 placentas displaying abnormal morphologies and connected to dead fetuses (late resorptions) had a high contribution of mutant cells, whereas the phenotype-lacking placenta connected to the live E17.5 chimeric fetus displayed a very low contribution of mutant cells (Fig. 4A). Chimeric placentas isolated at $\mathrm{E} 11.5$ all showed an equal contribution of mutant cells (data not shown). To determine the spatial distribution of mutant cells in E17.5 placentas, in situhybridization for the neomycin resistance gene was performed. Mutant cells were found to be present in the chorionic plate and in isolated islands within the labyrinth of the E17.5 D849V chimeric placentas (Fig. 4C and F). Interestingly, only a weak signal could be detected in the placenta attached to the live E17.5 D849V chimeric fetus, confirming the results from the semi-quantitative PCR (Fig. 4D and $\mathrm{G})$. Due to the lack of a phenotype, this placenta was not used for further analysis. As expected, no in situ hybridization signal was detected in wild-type placentas (Fig. 4B and E).

\section{Altered organization of the fetal blood vessel compartment in D849V chimeric placentas}

One marker for endothelial cells, PECAM-1 and two markers for pericytes, ASMA and NG2, were used to study the cellular organization of wild-type and D849V chimeric placentas in more detail. In the labyrinth of wild-type placentas the pericytes form pillar-like core structures around which the capillaries are organized (Fig. $5 A)$. This organization was lost in the labyrinth of high chimeric D849V placentas. In these placentas, the fetal vascular compartment was organized into island-like structures containing both PECAM-1 positive endothelial cells and ASMA-positive pericytes (Fig. 5A). A large number of these cells also expressed Pdgfrb (Fig. 5C). Immunohistochemistry using another pericyte marker, NG2, resulted in a staining pattern similar to that of ASMA (data not shown). Immunohistochemical staining for laminin revealed that the islands were lined with basal lamina. The immediate periphery of many cells within the islands also exhibited laminin immunoreactivity, but in a disorganized fibrilar or granular pattern (Fig. 5B).

Hyperproliferation of cells in the D849V chimeric placentas

BrdU labeling was used to study cell proliferation in the developing mouse placenta. As the expansion of the placenta 
slows down during late stages of gestation, the proliferation of cells decreases (Zechner et al., 2002). Accordingly, only a few cells were proliferating in the placentas from E17.5 wild-type fetuses. These were predominantly found in the chorionic plate. In addition, a few proliferating cells were found in the labyrinthine layer (Fig. 6A and C). A markedly higher number of cells were proliferating in the placentas from D849V E17.5 chimeric fetuses $(n=3 / 4)$. These placentas had an increased number of proliferating cells both in the chorionic plate and in the labyrinthine layer (Fig. 6B and D). Interestingly, the proliferating labyrinthine cells of these placentas were exclusively found within the island-like structures. Double stainings, using antibodies directed against BrdU together with antibodies recognizing either PECAM-1 or ASMA, showed that most of the cells proliferating within the island-like structures of the chimeric placentas were ASMApositive (Fig. 6E). A few proliferating PECAM-1 positive cells were also detected within these structures (Fig. 6F).

\section{The morphological changes observed in D849V chimeric} placentas are not caused by the death of the attached embryo

The dramatic morphological changes in E17.5 D849V chimeric placentas were only observed in placentas attached to dead embryos. In order to exclude that these morphological changes were a consequence of the death of the attached embryo, we also studied placentas from wild-type embryos killed by punctuation of the heart in utero at E13.5 and isolated four days later (E17.5). Placentas connected to the wild-type resorptions were atrophic (Fig. 7). These placentas were smaller in size and the cells of the labyrinthine layer were loosely arranged. The morphological changes of these placentas were clearly distinct from the changes caused by the D849V mutation. No structures corresponding to the characteristic stellate/fusiform-cell containing island-like struc-

A
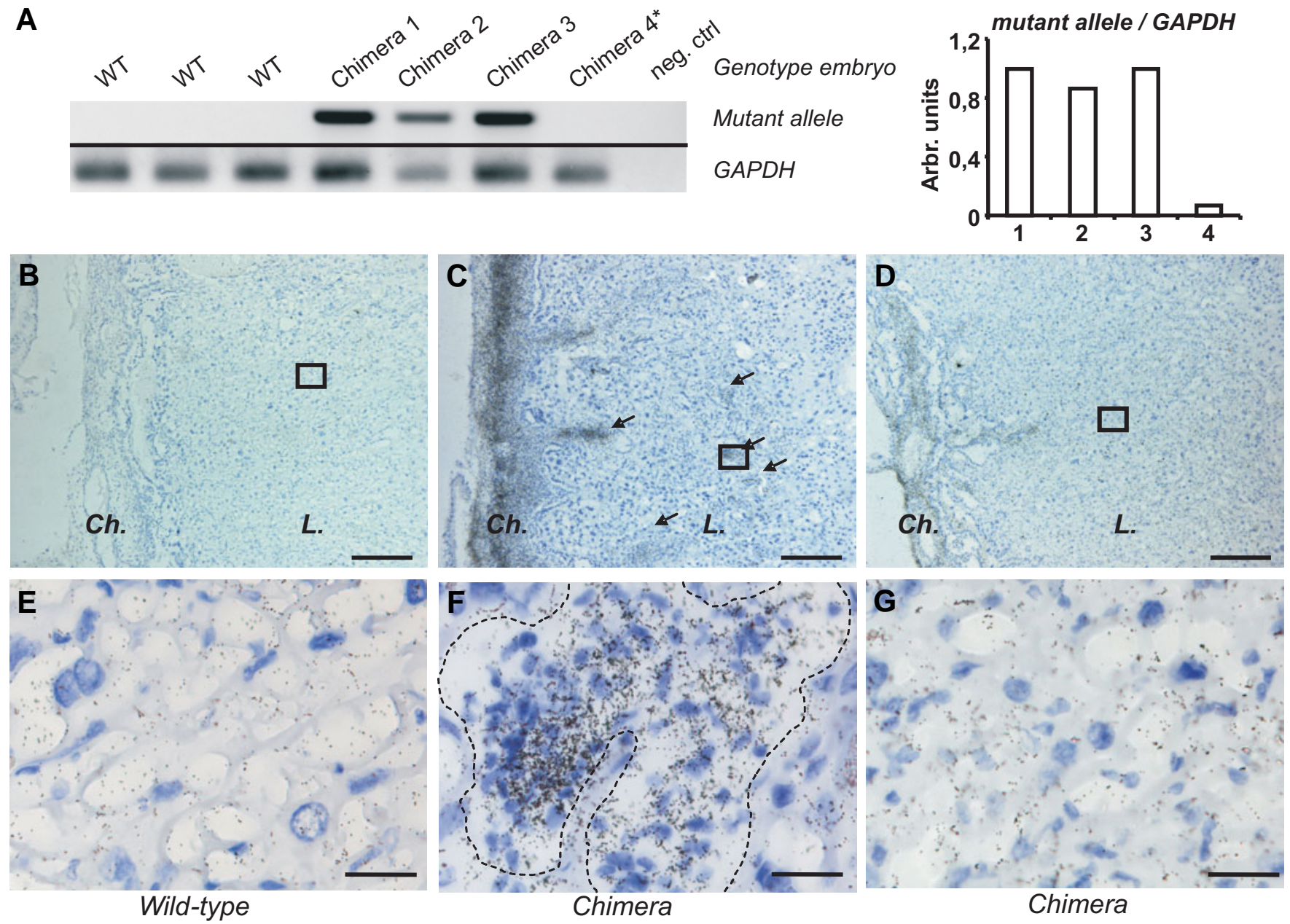

Chimera

Chimera

Fig. 4. Contribution and distribution of mutant cells within chimeric placentas. The contribution of mutant cells to the chimeric placentas was determined by PCR of the mutant allele on genomic DNA isolated from the labyrinth layer of E17.5 placentas (A). A Gapdh-specific PCR was used as an internal control for the input amount of genomic DNA. Quantification of the amount of PCR product from the mutant allele normalized against Gapdh levels is displayed in the graph to the right. The distribution of mutant cells in E17.5 placentas was determined by in situ hybridization analysis using a radioactive antisense riboprobe for the neomycin resistance gene. The neomycin resistance gene, indicating cells carrying the mutant allele, was expressed in the chorionic plate and in the island-like structures (arrows) of E17.5 chimeric placentas (C,F). Cells expressing the neomycin resistance gene were absent in E17.5 wild-type placentas (B,E) and contributed only marginally to the placenta of the only living E17.5 chimeric fetus (D,G). This chimera is marked with an asterix in (A). L, Labyrinth; Ch, chorionic plate. Bars: (B-D) $200 \mu \mathrm{m}$; (E-G) $25 \mu \mathrm{m}$. 
A
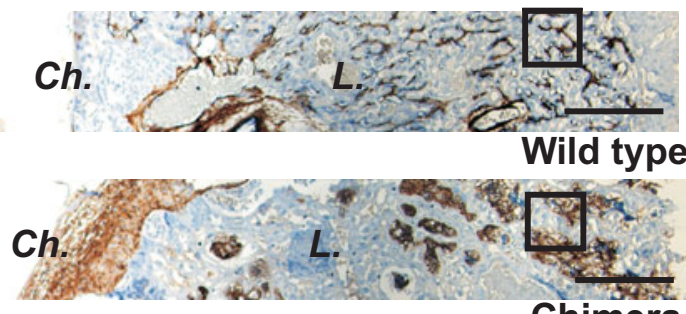

Chimera

B
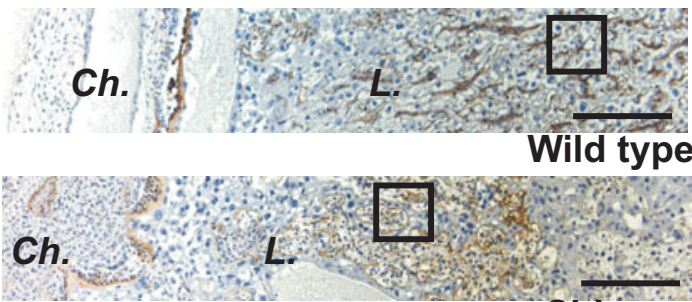

Chimera
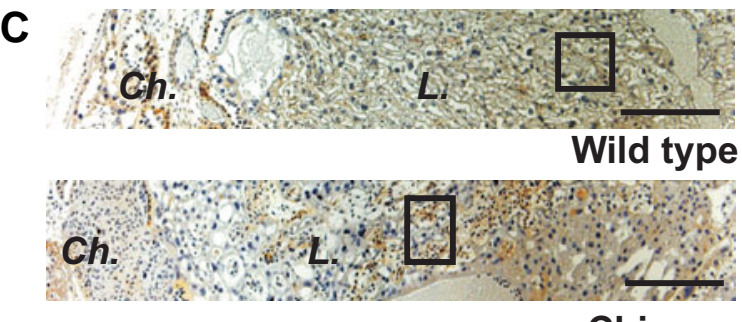

Chimera
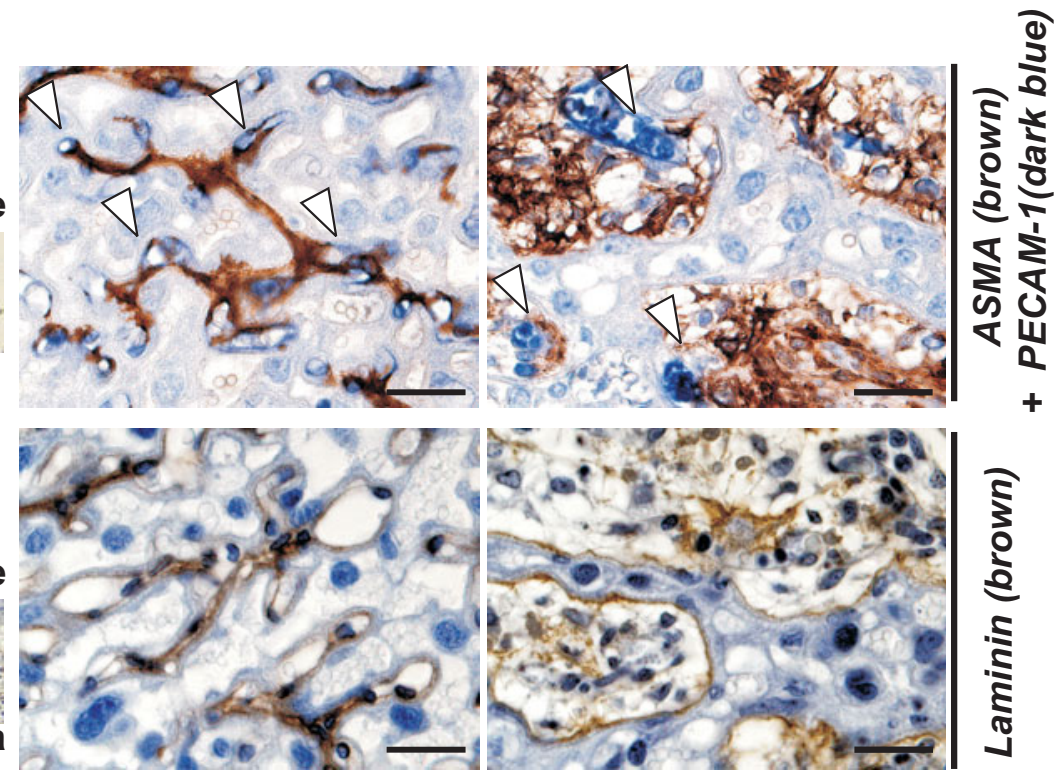

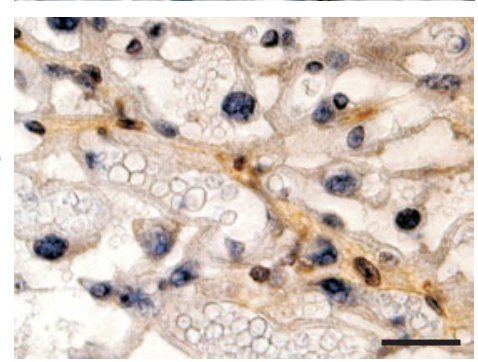

Wild-type

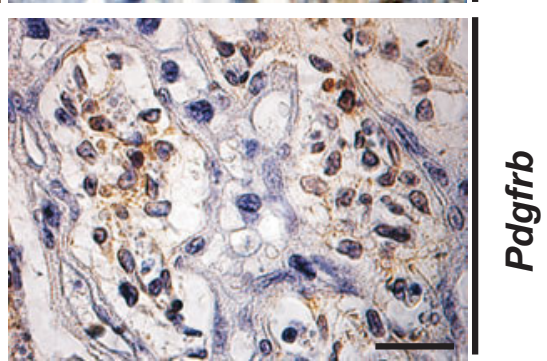

Chimera

Fig. 5. The D849V mutation in Pdgfrb causes changes in the fetal blood vessel compartment of the mouse placenta. ASMA (pericyte marker; brown) and PECAM-1 (endothelial cell marker; dark blue) double staining of wild-type and chimeric E17.5 placentas (A), counterstained with Mayer's hematoxylin (light blue). In wild-type placenta, the ASMA-positive cells form cores around which fetal capillaries (arrowheads) organize (A, middle column). In the chimeric placentas, the pericytes (ASMA+) and endothelial cells (PECAM-1+) are disorganized and found within island-like structures $(A$, right column). (B) Laminin staining of E17.5 chimeric placentas ( $B$, right column), counterstained with Mayer's hematoxylin, shows that these islands both contain and are surrounded by basement membrane. (C) Pdgfrb staining shows that a large proportion of the cells within these islands express the receptor (C, right column). Low magnification of wild-type and chimeric placentas are shown in the left column (bars, $200 \mu \mathrm{m}$ ) and higher magnifications from the same sections are shown both for wild-type (middle column) and chimeric placentas (right column). Bars: 25 um.

tures of the D849V chimeric placenta could be identified and, as determined from BrdU-labeling, the proliferation of cells in the wild-type placentas attached to resorbed embryos was similar to that of wild-type placentas attached to living embryos at the same gestational age (compare Fig. 6A, C and 7C, D).

\section{Discussion}

PDGF is a well-known mitogen and prolonged activation of Pdgfrb results in cellular proliferation (Westermark and Heldin, 1985). Over-expression of Pdgfb is associated with hyper-proliferative disorders, such as fibrotic conditions (reviewed in (Bonner, 2004)) and atherosclerosis (reviewed in Raines, 2004). Moreover, mutations resulting in over-expression of the genes encoding Pdgfb or Pdgfrb, or constitutive activation of Pdgfrb, e.g. by chromosomal translocation, are associated with malignant diseases (Ostman, 2004). Substitution of a highly conserved aspartic acid located in the activation loop of tyrosine kinase receptors including the KIT, Flt3 and Met receptors have been associated with tumor formation. This is also true for PDGF receptors as an exchange of valine for this conserved aspartic acid in the activation loop of Pdgfra (D842V) was recently associated with gastrointestinal tumors (Heinrich et al., 2003). This Pdgfra mutation has only been found as a somatic mutation (Heinrich et al., 2003), suggesting that it is not compatible with embryonic development. The D849V mutation in the Pdgfrb presented here turned out to be dominant embryonic lethal, since no viable coat chimeras were detected. Similar to the GIST-associated Pdgfra D842V mutation, the Pdgfrb D849V mutation is characterized by ligand-independent auto-phosphorylation of the receptor (Fig. 2A). The mutant receptor was also more sensitive to low concentrations of PDGFBB (Fig. 2A). We had previously introduced a similar mutation (D849N) into Pdgfrb, also with the aim to create an oncogenic mouse model for Pdgfrb. However, this mutation did not cause any overt phenotype in mice (Chiara et al., 2004). Both, the $\mathrm{D} 849 \mathrm{~N}$ mutation and the D849V mutation resulted in ligandindependent tyrosine phosphorylation of the respective receptors. However, when we compared individual tyrosine phosphorylation sites between the two mutant receptors, significant differences were observed as summarized graphically in figure 2B. 
Tyrosine residues 762, 1008 and 1020, the docking sites for the phosphatase Shp2 (pY762/pY1008) and phospholipase C- $\gamma$ (pY1008/pY1020), are phosphorylated in the D849V mutant receptor but not in the wild-type or D849N mutant receptor under non-stimulating conditions (Fig. 2B and data not shown; Chiara et al., 2004). Since both of these signal transducers are strongly connected to mitogenic signalling (Heldin and Westermark 1999), we compared wild-type and D849V mutant MEFs in proliferation assays. While the D849V mutant MEFs proliferated with maximal rate even in the absence of ligand, an increase in the proliferation of wild-type MEFs could only be detected in the presence of PDGF-BB, as expected (Fig. 2C). A strict dependence on PDGF-BB for cellular proliferation has also been noted in the D849N mutant fibroblasts and this ligand-dependence is the most probable reason for the lack of an oncogenic phenotype in these mice (Chiara et al., 2004). Therefore, the strong ligand-independent proliferation is a major difference between the D849V and D849N-mutant MEFs, which could very well contribute to phenotypic in vivo differences.

Pdgfb/Pdgfrb signalling is necessary for the normal development of blood vessels and for the proper cellular organization of different organs including the kidney, brain and placenta (reviewed in Betsholtz, 2004). The direct involvement in placental development was demonstrated by studies on placentas from Pdgfb and Pdgfrb null mutant mouse conceptuses. These placentas exhibited changes at the location for nutrient-waste exchange between mother and fetus, i.e. in the labyrinthine layer, characterized by dilated fetal blood vessels and reduced numbers of trophoblasts and pericytes (Ohlsson et al., 1999). In the present work, we describe the effects of an activating mutation (D849V) in the Pdgfrb on mouse placental development. The mutation caused cellular hyper-proliferation and disorganization of the fetal blood vessel compartment (Fig. 3, 5 and 6). These changes were clearly visible at E17.5, but not at $E 11.5$. The late onset of these changes was not surprising since significant levels of Pdgfb and Pdgfrb mRNA expression are first detected relatively late during placental development, starting at E12.5/13.5 (Bidwell et al., 1995, Ohlsson et al., 1999). In agreement with this late onset of expression, the effects of the Pdgfb and Pdgfrb null mutations on placental development were not visible before E13.5 (Ohlsson et al., 1999). In the present experimental setup, it is difficult to exclude that embryonic death preceded the changes observed in highly chimeric placentas. The morphological changes observed in E17.5 chimeric placentas attached to dead fetuses were, however, clearly distinct from those observed in wild-type E17.5 placentas attached to fetuses that had been killed in utero at E13.5. The presence of a hyper-active Pdgfrb signalling thus clearly induced excessive cellular proliferation and reorganization of the blood vessel compartment in highly D849V chimeric placentas.

Not all of the cells in the chimeric placentas carried the mutation, as these placentas developed from wild-type blasto-
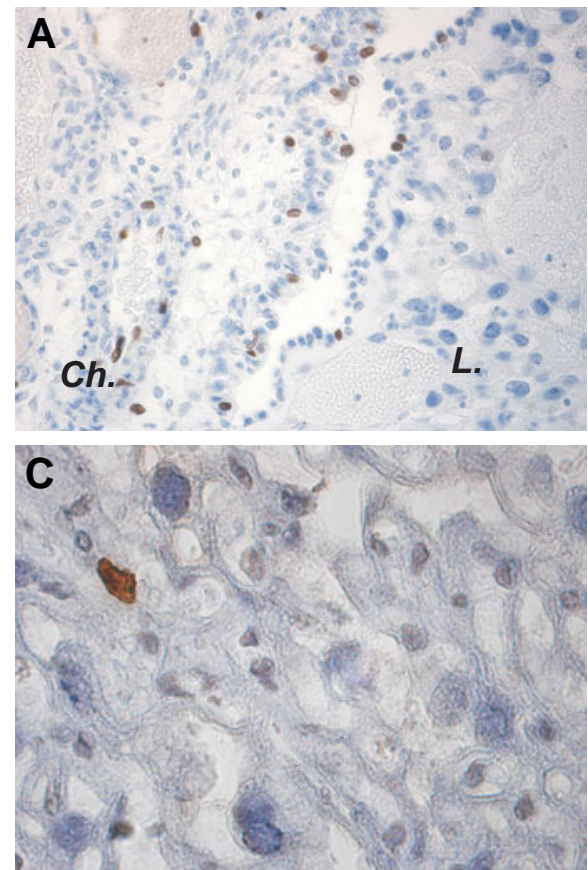

Wild-type
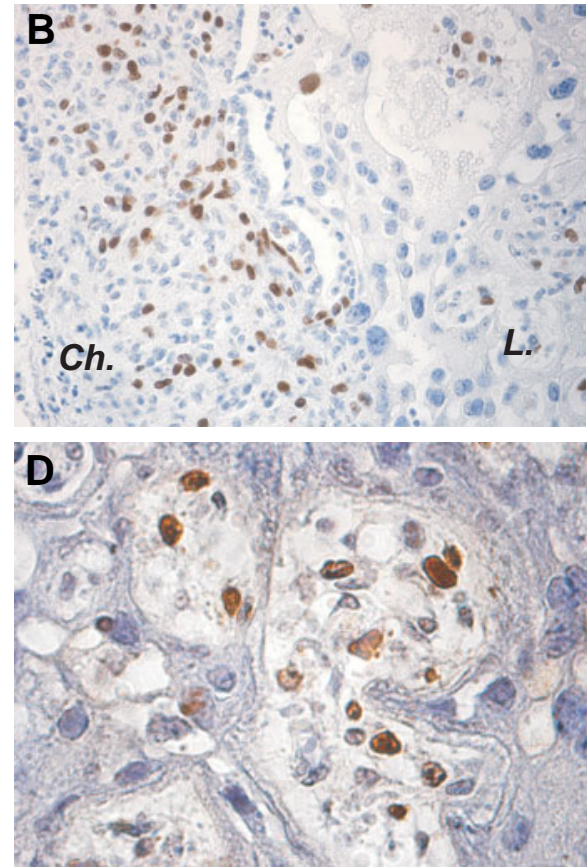

Chimera

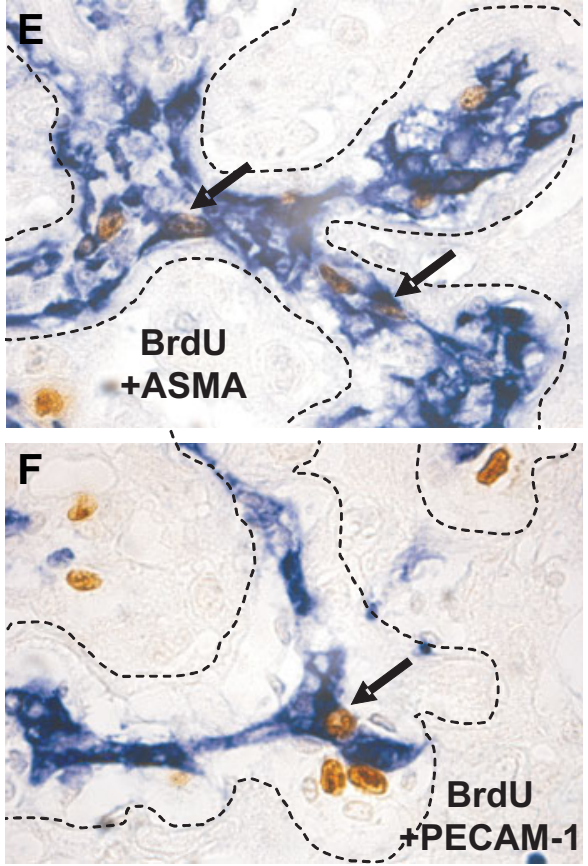

Chimera

Fig. 6. Cell proliferation in wild-type and chimeric E17.5 placentas. BrdU was used to label nuclei of proliferating cells in wild-type (A,C) and chimeric (B,D) E17.5 placentas. Note that the number of labelled nuclei (brown dots) is markedly higher in the chimeric placenta, both in the chorionic plate (compare $A$ and $B$ ) and in the labyrinth (compare $C$ and D). High magnification images of double stainings for (E) ASMA / BrdU (pericyte marker blue, BrdU brown) and (F) PECAM-1 / BrdU (endothelial marker marker blue, BrdU brown) of the labyrinth of a high chimeric placenta are also shown. Two from a total of seven BrdU+/ASMA + cells and one from a total of one BrdU+/PECAM-1+ cell are indicated by arrows. To more clearly identify double-positive cells of chimeric placentas, counterstaining was omitted in these preparations (E, F). A dashed help-line has been introduced at the edge of the island-like structures in (E) and (F). L, Labyrinth; Ch, chorionic plate. Bars: (A,D) $100 \mu \mathrm{m} ;(B, C, E, F, I, J) 25 \mu \mathrm{m} ;(G, H) 200 \mu \mathrm{m}$. 
cysts injected with mutant ES cells. Under these circumstances, the mutant ES cells contribute only to the chorionic plate and the cells of the embryonic blood vessel compartment in the labyrinthine layer, but not to the trophoblast lineages, which explains why the phenotypic changes were restricted to these two structures (Tam and Rossant, 2003). Furthermore, not all cell types express the Pdgfrb on their cell surface. Pericytes, however, have been shown to express the Pdgfrb. In line with this, the D849V chimeric placentas displayed increased proliferation of cells, most of which were positive for the pericyte markers ASMA and NG-2 (Fig. 6E and data not shown).

Accumulating data indicate that pericyte-endothelial interactions are important for the proper development of blood vessels (reviewed in Gerhardt and Betsholtz, 2003). The pericytes of the placenta and the equivalent cells of the kidney, the mesangial cells, have for instance, been suggested to be involved in intussusceptive splitting of capillaries, as the loss of these cell types in Pdgfb and Pdgfrb null mutants resulted in increased capillary calibre (Ohlsson et al., 1999). Furthermore, the migration of the Pdgfrb positive pericytes during angiogenesis is believed to be guided by a gradient of Pdgfb produced by specialized endothelial cells situated at the tip of the angiogenic sprout (reviewed in Betsholtz, 2004). Cells carrying a constitutively active Pdgfrb might have lost their ability to follow such an instructive Pdgfb gradient due to elevated ligand-independent migratory activity.

In light of previously published data and our own observations, we believe that the uncontrolled proliferation of mutant pericytes, together with a disturbed interaction between pericytes and endothelial cells, was the cause of the altered organization of the fetal vascular compartment observed in the Pdgfrb D849V chimeric placentas. The increased proliferation and reorganization of endothelial cells observed in the chimeric placentas were therefore most likely secondary to the increased pericyte proliferation. PDGF-stimulation of vascular mural cells has, for instance, been shown to induce the production of VEGF-A, a potent endothelial mitogen (Brogi et al., 1994, Dong etal., 2004, Stavri et al., 1995). It is thus conceivable that the increased endothelial cell proliferation is a consequence of the hyperactive Pdgfrb expressed on mutant pericytes.

\section{Materials and Methods}

\section{Animals}

A change from aspartic acid to valine was introduced at codon 849 of Pdgfrb using a targeting construct encompassing exons 16 through 21 of the Pdgfrb gene and harbouring point mutations in exon 17 (nucleotides encoding amino acid 849). The targeting construct was generated as described before (Chiara et al., 2004), using the following primers to introduce the mutations:

5-GACTTCGGCCTGGCTCGAGICATTATGAGGGACTCAAACTACA3 ' and

5'-TGTAGTTTGAGTCCCTCATAATGaCTCGAGCCAGGCCGAAGTC$3^{\prime}$

(base exchange resulting in amino acid exchange indicated in lowercase letters). Following sequence verification, the targeting construct was linearized with Not and electroporated into GS-1 ES cells (Genome systems). Correctly targeted ES cell clones were identified using previously described protocols (Heuchel et al., 1999). Briefly, homologous recombination events were screened by PCR, using primers for the neo gene and genomic sequence outside the targeting construct. Then, positive ES cell clones were tested by Southern blot using a probe complementary to genomic DNA 5' outside of the targeting construct. The neo cassette was not removed, since its presence at that specific position in intron 15 had been shown previously not to affect the expression of Pdgfrb (Chiara et al., 2004, Heuchel et al., 1999, Tallquist et al., 2000).

A total of 345 manipulated blastocysts (wild-type blastocysts injected with mutant cells; Uppsala University Transgenic Facility and Umeå Transgene Core Facility) were transferred (290 for clone 1 and 55 for clone 2). 19 pups were found alive at the day of birth. Of those, 7 died prior to fur development and the remaining 12 pups were wild type according to coat color. We also performed a control experiment where correctly targeted, but otherwise wild type ES cells (targeting vector had recombined at correct locus, but only the neocassette was integrated into the genome and not the point mutation, which is roughly 800 base pairs away from the neo selection cassette) were injected into wild type blastocysts. 74 of such chimeric wild type (for Pdgfrb) blastocysts were transferred. 12 pups were born. 6 turned out to be

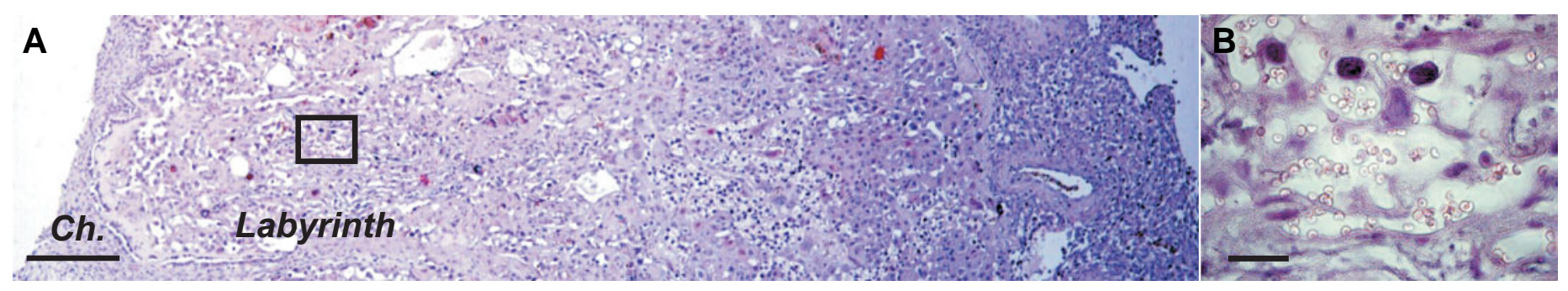

Fig. 7. Morphology of placentas attached to resorbed wild-type embryos. (A,B) Mayer's Hematoxylin-Eosin staining of a E17.5 placenta connected to a dead wildtype embryo. (B) A higher magnification of the labyrinthine layer, black rectangle in (A). Results from BrdU-labeling of proliferating cells are shown in (C,D), the latter showing high magnification of the labyrinthine layer. Labyrinth (L) and chorionic plate (Ch.) are indicated. Bars: (A) $200 \mu \mathrm{m}$; (B,D) $25 \mu \mathrm{m}$; (C) $50 \mu \mathrm{m}$.
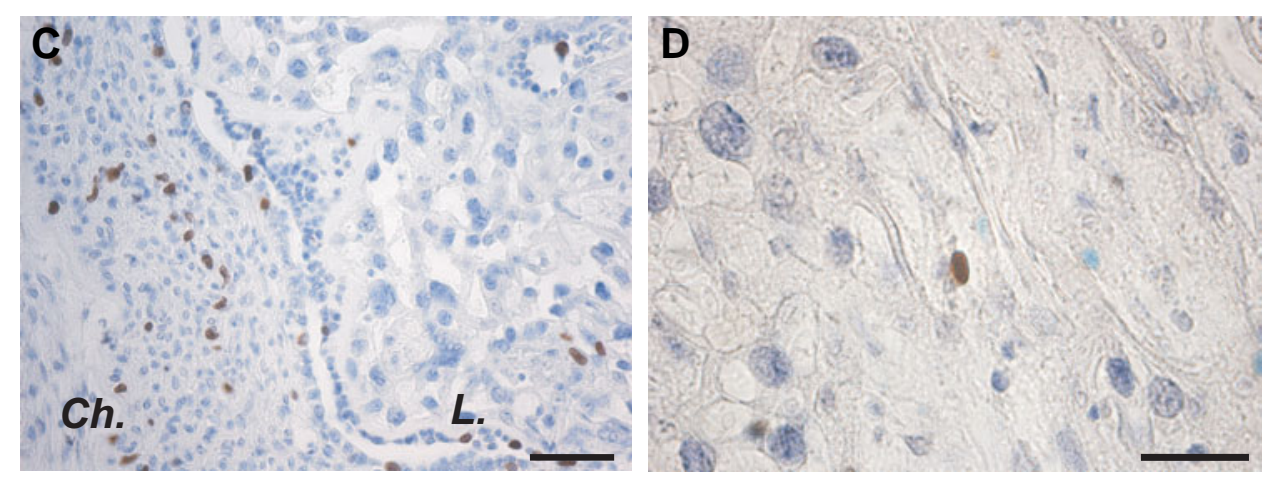
coat chimeras and 6 non-chimeric. $p=0.0001$ for the number of live pups born, wild type vs. chimeric blastocyst transfer (student's t-test, two-sample unequal variance/two-tailed distribution).

For the investigation of the placental phenotype, targeted ES cells were injected into C57BL/6 mouse blastocysts and transferred into the right uterus horn of pseudo-pregnant female mice. As a wild-type control, unmanipulated C57BL/6 mouse blastocysts were transferred into the left uterus horn of the same pseudo-pregnant female mice. Eight blastocysts were transferred into each uterus horn and the time of transfer was counted as E2.5. Placentas were isolated at E11.5, E13.5 and E17.5.

Pdgfrb (D849V/wild-type) chimeric conceptuses were identified by PCR using genomic DNA prepared from the tail (E17.5) or head (E11.5 and E13.5). Primers for genotyping were 5'-TTT GGG TTA GAC ACT TAG GAA T-3' (forward primer for wild-type and targeted allele); 5'-CAG CAG AGG GTT ATG GGT TAC T-3' (reverse primer for wild-type allele); 5'-TGG CTA CCC GTG ATA TTG CT-3' (reverse primer for targeted allele). Amplification of wild-type and mutant alleles results in $147 \mathrm{bp}$ and 582 bp products, respectively. The contribution of mutant cells to the chimeric placentas was determined by PCR using genomic DNA prepared from the labyrinthine layer of the placentas. Two $8 \mu \mathrm{m}$ sections from each placenta ( 3 chimeric and 5 wild type E11.5, 1 chimeric and 2 wild type E13.5 and 4 chimeric and 4 wild type E17.5 placentas) were deparaffinized and rehydrated. The labyrinthine layer of the placentas was then separated from the rest of the placenta under a microscope using a needle. The labyrinthine layer was then detached from the slide by addition of a small drop of detach solution ( $2 \%$ glycerol in $10 \mathrm{mM}$ Tris$\mathrm{HCl}, 1 \mathrm{mM}$ EDTA, pH 8.0) and DNA was extracted in DNA extraction buffer (100mM Tris- $\mathrm{HCl} \mathrm{pH} 8.0,1 \%$ Tween-20, $2 \mathrm{mg} / \mathrm{ml}$ proteinase $\mathrm{K}$ ). For amplification of the mutant allele, we used the same primers as mentioned above. The GAPDH gene was used as internal control for the PCR reaction. The PCR was run for 23 cycles using the following primers: 5 'ATC ATC TCC GCC CCT TCT GC-3' (forward primer), 5'-GGT CAT GAG CCC TTC CAC AAT-3' (reverse primer). For digital data analysis a FUJI CCD camera LAS-1000 was used in combination with Advanced Image Data Analyzer (AIDA) software, Version 3.10.

To study the morphology of wild-type placentas attached to resorbed embryos, embryos were killed in utero at E13.5 by puncture of the heart with a fine needle. The placentas from the resorbed embryos were isolated four days later, at E17.5 $(n=4$; two litters, two killed embryos per litter).

All animal handling was performed with ethical permission from the Uppsala University ethics committee.

\section{Cell culture, western blot analysis and mitogenesis assay}

Mouse embryonic fibroblasts (MEFs) were derived from E13.5 chimeric and wild-type embryos according to standard protocols (Chiara et al., 2004). Cells were grown in Dulbecco's modified Eagle's medium (Invitrogen), supplemented with 10\% fetal bovine serum (Sigma) and 0.1 $\mathrm{mM} \beta$-mercaptoethanol. In order to isolate mutant MEFs, cell cultures originating from chimeric embryos were treated with G418 (PAA Laboratories).

PDGF-BB stimulation of serum-starved $(0.05 \%$ for 48 hours) cells was performed for 5 minutes at $37^{\circ} \mathrm{C}$ using increasing concentrations of PDGF-BB (kindly provided by Creative Biomolecules) as indicated. For kinetic analysis, serum-starved $(0.05 \%$ for 48 hours) cells were incubated with PDGF-BB $(20 \mathrm{ng} / \mathrm{ml})$ for $5,10,30$ or 60 minutes. Protein extracts were obtained as described before (Chiara et al., 2004). The proteins were separated by SDS-electrophoresis (7\% polyacrylamide gel) and transferred to nitrocellulose membranes. The membranes were probed with anti-phosphotyrosine (PY99, sc-7020, Santa Cruz Biotechnology), antibodies recognizing phosphorylated tyrosines (described in Chiara et al., 2004) or antibodies directed against Pdgfrb. The Pdgfrb antibody was a rabbit polyclonal antibody raised against a GST fusion protein containing the $\mathrm{C}$-terminal amino acid residues of $\mathrm{Pdgfrb}$. For digital data analysis a FUJI CCD camera LAS-1000 was used in combination with Advanced Image Data Analyzer (AIDA) software, Version 3.10. The experiment was repeated 3 times. Figure $2 A$ shows a representative blot.

For the mitogenesis assay, MEFs were seeded in 12-well plates and grown for $24 \mathrm{~h}$. The medium was then changed to starvation medium (Dulbecco's modified Eagle's medium supplemented by 1\% FCS) and after $24 \mathrm{~h}, 0.2 \mu \mathrm{Ci} / \mathrm{ml}[3 \mathrm{H}]$ thymidine (Amersham Biosciences) and PDGFBB $(0-25 \mathrm{ng} / \mathrm{ml})$ were added and the incubation was continued for $20 \mathrm{~h}$. Incorporated radioactivity was precipitated using $5 \%$ trichloroacetic acid and then dissolved in $1 \mathrm{M} \mathrm{NaOH}$. After neutralization, incorporated radioactivity was determined in a liquid scintillation counter. The experiment was repeated 3 times. Figure $2 \mathrm{~B}$ shows one representative experiment.

\section{Histological analysis and immunohistochemistry}

Placentas were processed for histology by fixation in Carnoy's $(60 \%$ ethanol, $30 \%$ chloroform, $10 \%$ acetic acid) or Serra's (60\% ethanol, $30 \%$ formalin, $10 \%$ acetic acid) fixative, followed by paraffin embedding and sectioning. Six to eight $\mu \mathrm{m}$ thick sections were stained with Mayer's Hematoxylin-Eosin.

Staining of placental pericytes was done using antibodies directed against $\alpha$-smooth muscle actin (ASMA; clone 1A4, M0851, DAKO diluted $1: 100)$ or NG2 chondroitin sulphate proteoglycan (AB5320, Chemicon international, diluted 1:100). The basement membrane of the blood vessel wall was stained using an antibody directed against laminin (L9393, Sigma, diluted 1:100). Endothelial cells were detected using an antibody recognizing platelet/endothelial cell adhesion molecule-1 (PECAM-1; M20, sc-1506, Santa Cruz, diluted 1:200) and Pdgfrb expressing cells were detected using the polyclonal rabbit antibody described above. All incubations with primary antibody were performed over night at $4^{\circ} \mathrm{C}$ and the binding of primary antibody was detected using biotinylated secondary antibodies recognizing mouse or rabbit antibodies (E0354 and E0432, respectively, both from DAKO and diluted 1:500), Vectastain ABC kits (PK-6100 or AK-5000 from Vector Laboratories) and peroxidase substrate kit (SK-4100, vector laboratories) or NBT/BCIP solution (1681451, Roche). Three chimeric and 5 wild type E11.5, 1 chimeric and 2 wild type E13.5 and 4 chimeric and 4 wild type E17.5 placentas were used for histological and immunohistochemical analysis.

\section{BrdU labeling}

Proliferating cells were labelled by intraperitoneal injection of bromodeoxyuridine (BrdU; B-5002, Sigma, $50 \mu \mathrm{g} / \mathrm{g}$ body weight) of the pregnant mother, 10 minutes (E11.5 and E13.5) or 60 minutes (E17.5) prior to isolation of the conceptuses. The tissues were fixed as described above, embedded in paraffin and sectioned $(6 \mu \mathrm{m})$. BrdU incorporation into replicating DNA was detected using an anti-BrdU antibody (clone BU-1, RPN202, Amersham Biosciences). All mice included in the study were injected with BrdU and 3 chimeric and 5 wild type E11.5, 1 chimeric and 2 wild type E13.5 and 4 chimeric and 4 wild type E17.5 placentas were analysed.

\section{In situ hybridization}

In situhybridization analysis was performed on $6 \mu \mathrm{m}$ paraffin sections of placentas fixed in Serra's fixative using ${ }^{35}$ S-labeled ribopobes, as described (Krause et al., 1999). Sense and antisense neomycin riboprobes were transcribed from a pBluescript vector containing only the coding region of the neomycin resistance gene. To generate the antisense riboprobe, the modified PGKneo.bpA vector was linearized with KpH and transcribed with RNA polymerase T7. To generate the sense probe, the vector was linearized with Sad and transcribed with RNA polymerase T3. In situ hybridizations were performed on three sections from each placenta (four wild-type and four chimeric E17.5 placentas).

\section{Acknowledgements}

R. Fundele was supported by grants from the Swedish Research 


\section{Council (Vetenskapsrådet) and by the Wallenberg Consortium North.}

\section{References}

BETSHOLTZ, C. (2004). Insight into the physiological functions of pdgf through genetic studies in mice. Cytokine Growth Factor Rev 15: 215-28.

BIDWELL, M.C., EITZMAN, B.A., WALMER, D.K., MCLACHLAN, J.A. and GRAY, K.D. (1995). Analysis of messenger ribonucleic acid and protein for the ligands and receptors of the platelet-derived growth factor signaling pathway in the placenta, extraembryonic membranes and uterus during the latter half of murine gestation. Endocrinology 136: 5189-201.

BONNER, J.C. (2004). Regulation of pdgf and its receptors in fibrotic diseases. Cytokine Growth Factor Rev 15: 255-73.

BROGI, E., WU, T., NAMIKI, A. and ISNER, J.M. (1994). Indirect angiogenic cytokines upregulate vegf and bfgf gene expression in vascular smooth muscle cells, whereas hypoxia upregulates vegf expression only. Circulation 90: 64952.

CHIARA, F., GOUMANS, M.J., FORSBERG, H., AHGREN, A., RASOlA, A., ASPENSTROM, P., WERNSTEDT, C., HELLBERG, C., HELDIN, C.H. and HEUCHEL, R. (2004). A gain of function mutation in the activation loop of platelet-derived growth factor beta-receptor deregulates its kinase activity. $J$ Biol Chem 279: 42516-27.

DONG, J., GRUNSTEIN, J., TEJADA, M., PEALE, F., FRANTZ, G., LIANG, W.C., BAI, W., YU, L., KOWALSKI, J., LIANG, X. et al. (2004). Vegf-null cells require pdgfr alpha signaling-mediated stromal fibroblast recruitment for tumorigenesis. EMBO J23: 2800-10.

GERHARDT, H. and BETSHOLTZ, C. (2003). Endothelial-pericyte interactions in angiogenesis. Cell Tissue Res 314: 15-23.

HEINRICH, M.C., CORLESS, C.L., DUENSING, A., MCGREEVEY, L., CHEN, C.J., JOSEPH, N., SINGER, S., GRIFFITH, D.J., HALEY, A., TOWN, A. et al. (2003). Pdgfra activating mutations in gastrointestinal stromal tumors. Science 299: 708-10.

HELDIN, C.H. and WESTERMARK, B. (1999). Mechanism of action and in vivo role of platelet-derived growth factor. Physiol Rev 79: 1283-316.

HELLSTROM, M., KALEN, M., LINDAHL, P., ABRAMSSON, A. and BETSHOLTZ, C. (1999). Role of pdgf-b and pdgfr-beta in recruitment of vascular smooth muscle cells and pericytes during embryonic blood vessel formation in the mouse. Development 126: 3047-55.

HEUCHEL, R., BERG, A., TALLQUIST, M., AHLEN, K., REED, R.K., RUBIN, K., CLAESSON-WELSH, L., HELDIN, C.H. and SORIANO, P. (1999). Plateletderived growth factor beta receptor regulates interstitial fluid homeostasis through phosphatidylinositol-3' kinase signaling. Proc Nat/ Acad Sci USA 96: 11410-5.
KRAUSE, R., HEMBERGER, M., HIMMELBAUER, H., KALSCHEUER, V. and FUNDELE, R.H. (1999). Identification and characterization of g90, a novel mouse rna that lacks an extensive open reading frame. Gene 232: 35-42.

LINDAHL, P., JOHANSSON, B.R., LEVEEN, P. and BETSHOLTZ, C. (1997). Pericyte loss and microaneurysm formation in pdgf-b-deficient mice. Science 277: $242-5$.

OHLSSON, R., FALCK, P., HELlSTROM, M., LINDAHL, P., BOSTROM, H., FRANKLIN, G., AHRLUND-RICHTER, L., POLLARD, J., SORIANO, P. and BETSHOLTZ, C. (1999). Pdgfb regulates the development of the labyrinthine layer of the mouse fetal placenta. Dev Bio/212: 124-36.

OSTMAN, A. (2004). Pdgf receptors-mediators of autocrine tumor growth and regulators of tumor vasculature and stroma. Cytokine Growth Factor Rev 15: 275-86.

RAINES, E.W. (2004). Pdgf and cardiovascular disease. Cytokine Growth Factor Rev 15: 237-54.

ROSSANT, J. and CROSS, J.C. (2001). Placental development: Lessons from mouse mutants. Nat Rev Genet 2: 538-48.

STAVRI, G.T., HONG, Y., ZACHARY, I.C., BREIER, G., BASKERVILLE, P.A., YLAHERTTUALA, S., RISAU, W., MARTIN, J.F. and ERUSALIMSKY, J.D. (1995). Hypoxia and platelet-derived growth factor-bb synergistically upregulate the expression of vascular endothelial growth factor in vascular smooth muscle cells. FEBS Lett 358: 311-5.

TALLQUIST, M.D., KLINGHOFFER, R.A., HEUCHEL, R., MUETING-NELSEN, P.F., CORRIN, P.D., HELDIN, C.H., JOHNSON, R.J. and SORIANO, P. (2000). Retention of pdgfr-beta function in mice in the absence of phosphatidylinositol 3'-kinase and phospholipase cgamma signaling pathways. Genes Dev 14: 3179-90.

TAM, P.P. and ROSSANT, J. (2003). Mouse embryonic chimeras: Tools for studying mammalian development. Development 130: 6155-63.

WESTERMARK, B. and HELDIN, C.H. (1985). Similar action of platelet-derived growth factor and epidermal growth factor in the prereplicative phase of human fibroblasts suggests a common intracellular pathway. J Cell Physio/124: 43-8.

ZECHNER, U., HEMBERGER, M., CONSTANCIA, M., ORTH, A., DRAGATSIS, I., LUTTGES, A., HAMEISTER, H. and FUNDELE, R. (2002). Proliferation and growth factor expression in abnormally enlarged placentas of mouse interspecific hybrids. Dev Dyn 224: 125-34.

Received: 5th March 2007 Reviewed by Referees: 21st March 2007 Modified by Authors and Accepted for Publication: 19th April 2007 Published Online: 25th June 2007 Edited by: Christine Mummery

\section{Previously published, related Int. J. Dev. Biol. articles of interest}

See our forthcoming Special Issue on The Placenta edited by Joan Hunt and Kent Thornburg at: http://www.intjdevbiol.com

A simple in vivo approach to investigate invasive trophoblast cells Juan A. Arroyo, Toshihiro Konno, Darya C. Khalili and Michael J. Soares Int. J. Dev. Biol. (2005) 49: 977-980 


\section{Teaching Developmental Biology}

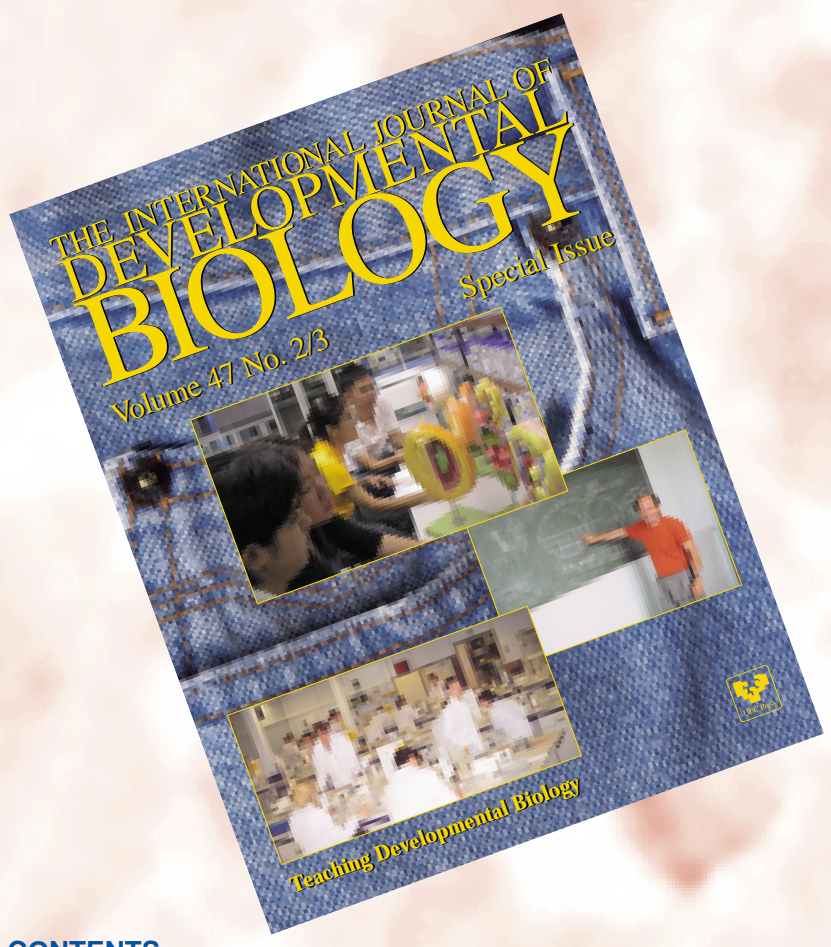

\section{An invaluable resource for researchers with teaching responsabilities!}

\section{CONTENTS}

Introductory Papers

Towards enriching the classroom experience

by George M. Malacinski and Susan T. Duhon

Setting the stage: developmental biology in the precollege classroom

by Sandra Borland, Karen Crawford and Victoria Brand

Examples of Undergraduate Developmental Biology Courses From field to gel blot: teaching a holistic view of developmental phenomena to undergraduate biology students at the University of Tokyo

by Takashi Ariizumi and Makoto Asashima

Integrating developmental biology into the undergraduate curriculum at the University of Bath, United Kingdom by Jonathan M.W. Slack

Making developmental biology relevant to undergraduates in an era of economic rationalism in Australia

by Brian Key and Victor Nurcombe

Learning developmental biology has priority in the life sciences curriculum in Singapore

by Tit-Meng Lim

Developmental biology for undergraduate students at the University of Palermo, Italy

by Giovanni Giudice and Karoly Onorato

Student-oriented learning: an inquiry-based developmental biology lecture course

by George M. Malacinski

Teaching embryology to undergraduates in the Faculty of

Education at Dokuz Eylul University in Izmir, Turkey

by Irfan Yilmaz

Teaching critical thinking in a developmental biology course at an American liberal arts college

by Dany S. Adams

Examples of College Laboratory Courses

Using Xenopus as a model system for an undergraduate

laboratory course in vertebrate development at the University of Bordeaux, France

by Michelle Olive, Pierre Thiebaud, Marc Landry, Michel Duvert, Alain Verna, Wilfrid Barillot and Nadine Theze

The color purple: analyzing alkaline phosphatase expression in experimentally manipulated sea urchin embryos in an undergraduate developmental biology course by Julie Drawbridge

Chick embryo culture techniques employed at Karnatak University in Dharwad, India for studying cellular and molecular aspects of morphogenesis

by Sohan P. Modak

Examples of Advanced and/or Graduate-Level Developmental Biology Courses

An intense half-semester developmental biology course, as taught at Uppsala University, Sweden

by Lennart Olsson

Integrating self-organization theory into an advanced course on morphogenesis at Moscow State University

by Lev V. Beloussov

Reverse engineering the embryo: a graduate course in developmental biology for engineering students at the University of Manitoba, Canada

by Richard Gordon and Cameron A. Melvin

Personal Journeys through Teaching Developmental Biology Developmental biology in Ecuador: a 30-year teaching experience

by Eugenia M. Del Pino

Four decades of teaching developmental biology in Germany by Horst Grunz

My perpetual cycle: from student to researcher to teacher to student...

by Robert Vignali

Course Enhancements and Alternative Learning Strategies Course enhancement: a road map for devising active-learning and inquiry-based science courses

by William $S$. Harwood

The role of textbooks in communicating developmental biology by Leon W. Browder

Using models to enhance the intellectual content of learning in developmental biology

by John C. McLachlan

Virtual labs: a substitute for traditional labs?

by Rebecca K. Scheckler

Broadening the Teaching Agenda beyond Traditional Content Emphases

Educating for social responsibility: changing the syllabus of developmental biology

by Scott F. Gilbert and Anne Fausto-Sterling

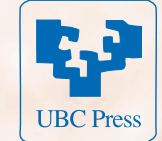

The International Journal of D evelopmental Biology Volume 47 No.2/ 3 (Special Issue) 2003 Order by web at: http:/ / www.ijdb.ehu.es (price 70 US\$ or $€$ ) 